\title{
A PCM based cooling system for office buildings: a state of the art review
}

\author{
Evdoxia Paroutoglou ${ }^{{ }^{*}}$, Alireza Afshari ${ }^{l}$, Niels Chr. Bergsøe ${ }^{l}$, Peter Fojan ${ }^{2}$, Göran Hultmark ${ }^{I}$ \\ ${ }^{1}$ Danish Building Research Institute, Aalborg University, Department of Energy Performance, Indoor Environment and Sustainability of \\ buildings, 2450 København SV, Denmark \\ ${ }^{2}$ Aalborg University, Department of materials science and engineering, 9220 Aalborg Ø, Denmark
}

\begin{abstract}
Cooling of air in buildings has a significant effect on thermal comfort and, consequently, productivity of office occupants. This study presents a state of the art review of energy efficient cooling systems that will provide occupants in buildings with satisfying thermal comfort. Using high-temperature cooling systems combined with renewable energy sources increases the energy efficiency in buildings. Latent heat thermal energy storage (LHTES) using Phase Change Materials (PCM) is a renewable energy source implemented in space cooling applications due to its high energy storage density. Since the share of commercial buildings in need of cooling is increasing, there is a need for developing new technical solutions in order to reduce the energy use without compromising thermal comfort. To this end, a proposed ventilation system, preliminarily analyzed in this paper, is expected to reduce further the energy use. The ventilation system is composed of an air handling unit, a 2-pipe active chilled beam system, and a cooling system including a LHTES using PCM. Few researchers have investigated chilled water air-conditioning systems that integrate a LHTES using PCM. In this review, function characteristics, possibilities and limitations of existing systems are discussed.
\end{abstract}

\section{Introduction}

International Energy Agency (IEA) estimates that the energy use in the building sector covers around $40 \%$ of the total primary energy use in the United States (U.S.) and the European Union (EU) [1]. On the grounds of sustainable development, new energy efficiency policies for buildings have been adopted in the last decades, and new technologies have been developed. In this direction, the EU introduced the Nearly Zero Energy Buildings (nZEB) concept. In order to comply with the requirements of nZEB newly constructed and renovated buildings should reach nearly zero energy use [2]. Even though the thermal performance of buildings has improved, the cooling demands are rising progressively due to the global climate change [3]. According to Global CCS institute by 2020 the share of commercial buildings in Europe in need of cooling equipment is expected to increase up to $60 \%$ [4].

American Society of Heating, Refrigerating, and AirConditioning Engineers (ASHRAE) states that thermal comfort is "that condition of mind that expresses satisfaction with the thermal environment and is assessed by subjective evaluation" [5]. In addition to the energy demand, thermal comfort is of utmost significance for the occupant's well-being and productivity since it is estimated that people spend up to $90 \%$ of the time indoors [6]. It is acknowledged that a healthy indoor environment of a building is a result of a proper design, installation, and control of the HVAC system [7]. Thermal energy storage (TES) such as latent, sensible and chemical heat storage are used to shift the peak loads and provide high energy saving potential. Latent heat storage in building applications is achieved with the use of Phase Change Materials (PCM). The PCM applications, widely considered after world war II [8], contribute to the development of low energy HVAC systems with optimal thermal comfort performance.

\section{Phase Change Materials}

\subsection{Classification}

"PCMs are materials with high heat of fusion that can store or release energy by melting or solidifying at a specific temperature range"[9]. PCM are classified according to their change of state condition in different form: solid-solid PCMs [10], solid-liquid PCMs [11], and liquid-gas PCMs [12]. The solid-liquid PCMs (Figure 1) considered in heat energy storage applications are divided into three main categories: organic, inorganic and eutectics [13]. Organic PCMs such as paraffins which are crude oil products and fatty acids are commonly used in Thermal Energy Storage (TES) applications. The inorganic PCMs are divided into two categories: salt hydrates and metallics. Paraffins, fatty acids as well as salt hydrates have been widely used in building, HVAC, solar energy, electronics, spacecraft, textile and food industry applications [14],[15]. Until now metallic PCMs have been used in electronics applications [15]. The eutectic

Evdoxia Paroutoglou: EVP@sbi.aau.dk 
PCMs are binary or trinary mixtures of chemical compounds that melt and solidify congruently [9].

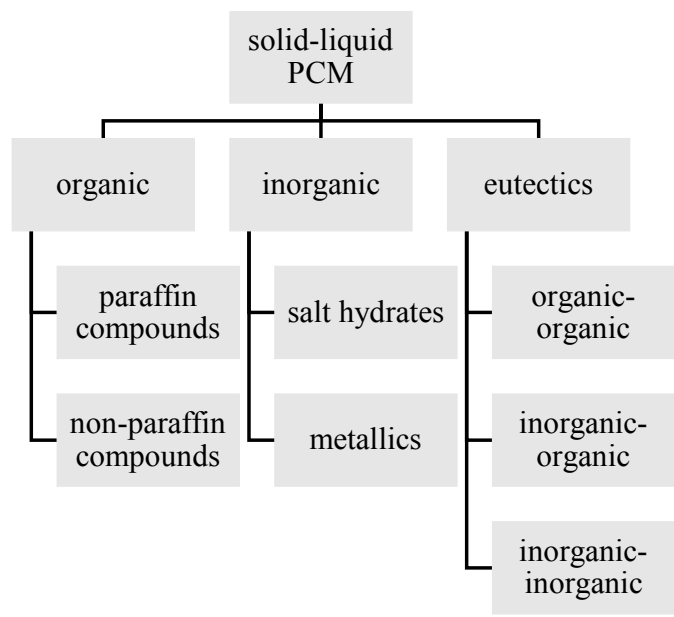

Figure 1: Classification of solid-liquid PCM

\subsection{Thermal properties and testing methods}

Several studies [16], [17], [18] are focused on the evaluation of the properties of PCMs.

Organic PCMs are regularly used in building envelope applications due to their favorable properties such as chemical and physical stability over repeated thermal cycles, no segregation, no corrosion, compatibility with different materials, no supercooling [19]. Conversely their flammability, low thermal conductivity and volume change are disadvantages of this category [17]. The inorganic PCMs are characterized by high thermal conductivity, small change in their volume, low cost and high heat of fusion, but supercooling and corrosion are effects commonly met in this category [19]. Metallic PCMs were recently attempted to be encapsulated and are proved to have high corrosivity and volume expansion. Eutectic PCMs tend to have a broad range of melting temperatures, high volumetric thermal storage and no segregation is observed throughout the thermal cycles [20]. The thermodynamic properties of PCM can be improved by implementing enhancement techniques such as metal foams, carbon fibers and expanded graphite [19].

Table 1: Testing methods of the thermal properties of PCM

\begin{tabular}{|l|c|}
\hline Testing method & Reference \\
\hline Differential Scanning Calorimetry (DSC) & {$[13]$} \\
\hline Differential Thermal Analysis (DTA) & {$[21]$} \\
\hline T-history method & {$[16]$} \\
\hline Thermogravimetric Analysis (TGA) & {$[22]$} \\
\hline
\end{tabular}

Differential Scanning Calorimetry (DSC) and Differential Thermal Analysis (DTA) are the most commonly used testing methods for the measurement of thermal properties. Both methods are used for the estimation of latent heat and require only a small and homogeneous sample. Another useful testing method of the PCM melting point, heat of fusion, specific heat and thermal conductivity is the T-history method developed by Zhang et al. [16]. Compared to DSC and DTA the T-history method considers a larger sample in a simplified set up. Thermogravimetric analysis (TG/TGA) is a method where the mass of the sample is measured under different temperatures.

\subsection{Incorporation methods}

The incorporation methods of PCM in building applications referred in the bibliography are direct incorporation, immersion and encapsulation [8]. In the direct incorporation technique the PCM in liquid or powder form is added in building materials. The immersion technique refers to impegnation of the building materials in melted PCM. The three types of encapsulation depending on the capsule size are macroencapsulation, microencapsulation and nanoencapsulation (Table 2). In macroencapsulation the PCM is encapsulated in a shell such as tubes, spheres or panels [23]. In microencapsulation the PCM particles in solid or liquid form constitute the core and are enclosed in a polymeric film to produce microcapsules [24]. By using the microencapsulation technique, the convective heat transfer coefficient can be increased. Nanoencapsulation is a novel method for encapsulating PCMs in nanoscale. Recent studies [17],[18],[25] indicate that the nanoencapsulation method can optimize the PCMs efficiency. Liu et al. [18] reviewed the preparation methods and application of NanoPCM and suggested further research on molten salt and hydrated salt encapsulation since most studies are focused on organic NanoPCM.

Table 2: Encapsulation methods of PCM

\begin{tabular}{|l|c|c|}
\hline Encapsulation method & Capsule size & Reference \\
\hline Macroencapsulation & $>1000 \mu \mathrm{m}$ & {$[26]$} \\
\hline Microencapsulation & $1-1000 \mu \mathrm{m}$ & {$[27]$} \\
\hline Nanoencapsulation & $1-1000 \mathrm{~nm}$ & {$[18]$} \\
\hline
\end{tabular}

\section{Latent Heat Thermal Energy Storage (LHTES) by incorporating PCM in the chilled water air conditioning (A/C) system}

\subsection{Heat exchangers arrangements}

PCM are able to store latent heat and several studies have focused on the energy saving potential in building applications. According to Kośny [9], PCM applications can reduce the energy use between $5-30 \%$ in residential buildings. PCMs inserted in cold storage devices for airconditioning applications is a method gaining ground in the HVAC technologies. Studies including PCM LHTES systems with water as heat transfer fluid (HTF) are analyzed in this review. The cold storage devices with PCM can be classified according to their construction to flat-plate, double tube, shell and tube, and compact fin and tube heat exchangers [28].

\subsubsection{Shell and tube configuration}

The factors which play an influential role in the shell and tube heat exhanger configuration were the inlet HTF 
temperature, the Prandtl number, the Reynolds number, the length and radius of the tube. Morcos [29] investigated a shell and dimpled finned tube heat exchanger and the PCM used was a mixture of asphalt and paraffin wax. The investigated heat exchanger was efficient for temperature differences between the HTF and the PCM phase transition lower than $16 \mathrm{~K}$. Lacroix [30] investigated the transient behavior of a shell and tube thermal energy storage. The author studied the effect of fins attached to the surface of inner tubes. It was concluded that mass flow rates in the range of $0.0015 \mathrm{~kg} / \mathrm{s}$ to $0.015 \mathrm{~kg} / \mathrm{s}$ and inlet temperature at +5 degrees above the PCM melting temperature for the HTF are favorable conditions for heat transfer enhancement [30]. Zhang and Faghri [31] have also studied the effect of fins attached internally in the tube for heat transfer enhancement, and the technique proved to be effective. Anica Trp et al. [32],[33] investigated a shell and tube latent thermal energy storage system and the PCM used was paraffin. The conclusion of this study was that the geometry of the system, as well as the operating conditions, must be based on the required heat transfer rate and the charging or discharging time [33]. Akgün et al. [34] performed an experimental study of a shell and tube latent heat thermal energy storage. Three kinds of paraffins tested as PCM filled the annular space between the tube and the outer shell. The shell surface was set to an inclination angle of $5^{\circ}$ in order to enhance the heat transfer, and improve the melting and solidification processes. Hosseini et al. [35] examined a shell and tube LHTES unit. The heat exchanger is comprised of a horizontal cylinder where the HTF flowed and a copper tube placed in the center of the cylinder filled with the paraffinic PCM [35]. The system was externally insulated by glasswool, and it included a charging and a discharging loop with hot and cold water respectively. The study demonstrated that by increasing the inlet HTF temperature the melting time of the PCM decreases and the theoretical efficiency of the heat exchanger increases [35].

\subsubsection{Triplex tube configuration}

Eslamnezhad and Rahimi investigated a triplex tube heat exchanger including rectangular fins [36]. The authors findings showed that the fins arrangement can increase the heat exchanger efficiency. A triplex tube heat exchanger with PCM for simultaneous charging and discharging was investigated by Joybari et al. [37]. In this study a numerical analysis was conducted. The PCM material was RT31, and different cases were tested depending on the heating mode and the condition of the storage. It was concluded that natural convection is not negligible for the examined configuration. A triplex concentric tube heat exchanger [38] was numerically analyzed and modeled in an experimental apparatus. The PCM filled the cavity of the middle channel. Hot water was the hot heat transfer fluid (HHTF) and cold water was the cold heat transfer fluid (CHTF) flowing outer and inner channel respectively [38]. The results indicated that higher mass flow rate $(0.011-0.012 \mathrm{~kg} / \mathrm{s})$, lower inlet temperature for charging $\left(23-25^{\circ} \mathrm{C}\right)$ and higher inlet temperature (63- $65^{\circ} \mathrm{C}$ ) for discharging led to a shorter solidification/melting time [38].

\subsubsection{Fin and tube heat exchangers}

A PCM fin and tube heat exchanger was examined by Wen-ju $\mathrm{Hu}$ et al. [39], and the study focused on the cooling charging and discharging characteristics of the thermal energy storage exchanger (TESE) using PCM. The heat transfer was enhanced with the addition of fins, and the PCM (RT5) was placed between the fins and the tubes. The thermal conductivity difference between liquid-solid PCM phase led to a higher discharging rate compared to the charging rate. Additionally, the inlet water temperature proved to be a high impact factor on the cooling characteristics of the examined system. Youssef et al. [40] created a physical and a numerical model of a spiral wired tube PCM heat exchanger. The thermal conductivity of the PCM was further increased due to the spiral wired tube arrangement. A 3D CFD model supported the accuracy of the experimental results. The HTF was a mixture of glycol and water. The convection heat transfer and buoyancy led to a faster charging time compared to the discharging time. It was shown that the higher the inlet flow rate the faster the melting and solidification processes.

\subsubsection{Double pipe heat exchanger arrangement}

Fath [41] investigated numerically and experimentally the performance of a double pipe heat exchanger. The stored energy and the heat transfer rate increased with an increase in the HTF inlet temperature, flow rate and length of storage. Balikowski et al. [42] investigated the charging and discharging characteristics of a double pipe heat exchanger. The authors tested the double pipe heat exchanger under two pipe configurations: a smooth and a spined pipe. The spined fins heat exchanger facilitated the charging and discharging rate through the fins-PCM direct contact. In addition, a higher water flow rate led to greater heat transfer between the HTF and the PCM.

Medrano et al. [43] studied five heat exchangers: three concentric tube heat exchangers, a compact fin-tube heat exchanger, and a plate heat exchanger. The compact fintube heat exchanger had by far the highest thermal power for both melting and solidification processes in cases with high-temperature difference between the HTF and the PCM.

The inlet temperature of the HTF, the mass flow rate of the HTF and the fins arrangement are the dominant influencing factors of the heat exchanger efficiency for all the examined heat exchanger configurations.

\subsection{Outdoor air for cooling}

Outdoor air is a sustainable energy source for free cooling of buildings. According to Maccarini et al. [44], Copenhagen weather condition facilitate the use of free cooling. More specifically for about $93 \%$ of the time in a year the temperature is below $18{ }^{\circ} \mathrm{C}$. The ambient temperature is for the greatest part of the year below the 
range $15-20^{\circ} \mathrm{C}[44]$. In this respect, a PCM with a melting temperature $15-20^{\circ} \mathrm{C}$ will enable the free cooling process for Copenhagen climate.

\subsection{Chilled water A/C systems with PCM}

Systems that integrate a Latent Heat Thermal Energy Storage unit with PCM connected to chilled water airconditioning systems are currently investigated by researchers in the HVAC technologies. This Latent heat storage technology promotes the electrical energy use to the off-peak time.

In the majority of the reviewed studies, the examined LHTES units connected to chilled water A/C systems are PCM storage tanks. Li et al. [45] modeled an A/C system composed by a refrigeration system and a storage tank. The authors looked at the effects of inlet temperature and refrigerant flow on the system. The results showed that the higher the water flow the faster the charging and discharging rate of the PCM in the storage tank. Wu et al. [46] analyzed the mathematical model of a cold thermal energy storage including a packed bed of spherical capsules with n-tetradecane. The simulations' results indicated that the rate of stored and released energy were at a higher level at higher flow rates of the HTF. Lower inlet temperature leads to higher stored energy rate during the charging cycle and lower released energy rate in the discharging cycle.

Parameswaran et al. [47],[48] examined a VAV chilled water air conditioning TES system with spherical PCM encapsulation. The system was tested in a summer and in a winter simulation period for a demand controlled ventilation (DCV) and economizer cycle ventilation (ECV) mode. In the ECV mode outdoor air was provided through the air damper and the chiller was set to $40 \%$ of the nominal capacity [47]. A $28 \%$ and $47 \%$ on peak energy saving was achieved for the DCV and DCV-ECV mode compared with the conventional constant air volume (CAV) air conditioning system. In a later study [48] the authors investigated the effect of a silver nanobased PCM thermal energy storage system incorporated to the DCV and ECV system. The incorporation of silver nanoparticles PCM improved the heat transfer processes through charging and discharging cycles. Falco et al. [49] investigated a chiller-fan coil system integrated with a PCM storage tank. The authors created a $5 \mathrm{kWh}$ prototype consisting of a PET tank with a mixture of RT5HC PCM and distilled water in direct contact. It was concluded that a charging power of $5.7 \mathrm{~kW}$ for 54 minutes was capable of charging the storage tank. Moreover, by increasing by $15 \%$ the volume of the PCM in the mixture, the stored energy increased by $24 \%$. It was underlined that a small office could reduce the electricity use by $13-16 \%$ with the implementation of the developed system. Zhao and Tan [50] performed a numerical analysis and created a model of a PCM shell and tube heat storage integrated with an air-conditioning system. The used PCM was RT22 with a phase change temperature of $19-23^{\circ} \mathrm{C}$. The HTF was air during the night-discharging cycle and water during the day-charging circle. Throughout the charging cycle the PCM absorbed heat from the water, flowing through the inner tube and the PCM liquified. In the discharging cycle outdoor air flowed between outer tube-shell and the PCM solidified. The coefficient of performance (COP) value of the proposed system has shown an increase of about $25 \%$ compared to a conventional system.

Experiments, as well as numerical analysis for a TES unit [51] combining three PCMs namely HS-W1, HS-W2 and Paraffin C15, showed that the 1:2:3 proportions combination acquired the largest charging capacity. In the same study, it was validated that the HTF flow rate did not have significant impact on the charging time.

Bruno, Tay, and Belusko [52] performed simulations of a PCM thermal energy storage coupled to a domestic chiller cooling system. The effectiveness-number of transfer units method ( $\varepsilon$-NTUs) was used in the simulations to calculate the heat transfer. The study targeted the investigation of the off-peak energy saving. The use of a $\mathrm{PCM}$ of a melting point at $10^{\circ} \mathrm{C}$ led to a $13.5 \%$ energy saving. The highest impact factors on the energy performance of the system were the thermal conductivity of the PCM as well as the charging time during colder periods. In another study Tay Belusko and Bruno [53] identified the effectiveness of the thermal energy storage connected to a chilled beams system. The storage effectiveness was found to be between $68 \%$ and $75 \%$.

\section{Thermal energy storage with PCM incorporated into a two-pipe chilled beam system}

\subsection{Chilled beam systems}

The terminal units of the most commonly used airconditioning systems where water is the medium of heat transfer are fan coils, climatic ceilings and chilled beams [13]. Mechanical ventilation and cooling are combined with the use of chilled beams in office buildings. As stated in REHVA guidebook [54] chilled beams for cooling should be used in buildings when the cooling demand is less than $80 \mathrm{~W} / \mathrm{m}^{2}$, the humidity levels are controlled, and the Building Management System (BMS) is adjusted in case of openable windows. Chilled beams have become a preferred solution because they contribute to energy and space savings, satisfactory thermal comfort and they have no need for regular maintenance. It has been demonstrated that chilled beams use less energy than conventional VAV systems to achieve the same level of thermal comfort.

Chilled beam systems can be divided into two categories: passive and active chilled beam systems. Passive or static chilled beam systems operate with natural air convection while active chilled beam systems are connected both to primary air and to chilled and heated water systems [54].

\subsection{Innovative two-pipe chilled beam system}

Active chilled beam systems can be divided into two configurations: two pipe systems and four pipe systems. The two pipe system configuration is constituted by a supply and a return water pipe which indicates that all the 
served zones will receive cold or hot water. The four-pipe configuration includes two supply and two return water pipes. In this way, hot and cold water can be distributed to the building zones simultaneously [55]. Research conducted at Danish Building Research Institute (SBi), Aalborg University, Copenhagen (SBi/AAU) in collaboration with Lindab Comfort A/S has initially set the requirements for the development of a two-pipe system for simultaneous heating and cooling of office buildings. Maccarini [56] designed and developed a novel two-pipe chilled beam system for simultaneous heating and cooling. The analysis was supported by simulations in Dymola. It has been shown that the two-pipe system uses between $12 \%$ and $18 \%$ less total annual primary energy compared to a conventional four pipes system. In the two-pipe chilled beam system for simultaneous heating and cooling the energy is transferred between warm and cold zones, and thus energy saving is achieved with a high degree of thermal comfort. Additionally, in the two-pipe chilled beam system for simultaneous heating and cooling fewer components are needed compared to a conventional four pipes system. The twopipe chilled beam system requires only one water pump, fewer pipes, and no control valves.

\subsection{Novel LHTES with PCM incorporated into 2 pipes chilled beam system}

This state of the art review makes up part of the foundation for an ongoing project. In this project it is aimed to develop- an innovative ventilation system with a cooling system which will integrate active chilled beams as terminal units and use a novel heat exchanger with PCM. The system that is going to be developed will use fewer resources in terms of materials and use significantly less cooling energy compared to a traditional chilled beam system. Calculations performed by Maccarini et al. [44] have shown that an integration of a thermal energy storage with PCM in this system can allow an energy reduction by $67 \%$ compared to the initial system. PCMs with a phase change temperature between 15 and $20^{\circ} \mathrm{C}$ will be preferred since this range is feasible for both charging and discharging phase.

A novel heat exchanger will be designed and constructed which will encapsulate a PCM layer to absorb the rejected heat from the building during occupied hours and release it to the environment during the night. In the charging phase that occurs during night hours, the cold outdoor air cools down the PCM which changes state from liquid to solid. During night operation lamellas open and the fan blows outdoor air towards finned tubes in order to solidify the PCM and store the cooling energy (Figure 2). In the discharging phase which occurs during occupied hours (daytime) the PCM absorbs heat from the return water flow of the system changing state from solid to liquid. The novel heat exchanger will be integrated into a two-pipe chilled beam system. A back-up chiller may be needed in the peak load days.

Table 3 is a list of the PCM with a melting temperature between 15 and $20^{\circ} \mathrm{C}$ used in experimental and analytical studies consequently.
Table 3: PCM materials with melting temperature $15-20^{\circ} \mathrm{C}$

\begin{tabular}{|c|c|c|c|}
\hline Material & $\begin{array}{c}\text { Melting } \\
\text { temperature } \\
\left({ }^{\circ} \mathrm{C}\right) \\
\end{array}$ & $\begin{array}{c}\text { Melting } \\
\text { enthalpy } \\
(\mathrm{kJ} / \mathrm{kg}) \\
\end{array}$ & Ref. \\
\hline \multicolumn{4}{|c|}{ Organic PCM- Paraffins } \\
\hline Hexadecane & 18 & 236 & [57] \\
\hline RT20 & 20 & 142 & {$[58]$} \\
\hline PCM-A16 & $15-17$ & 213 & [40] \\
\hline $\mathrm{C} 16$ & 18.2 & 238 & [59] \\
\hline RT 15 & 15 & 155 & [60] \\
\hline RT $18 \mathrm{HC}$ & 18 & 260 & [61] \\
\hline \multicolumn{4}{|c|}{ Organic PCM- Non-Paraffins } \\
\hline Acetic acid & 16.7 & 184 & {$[62]$} \\
\hline Caprylic acid & 16.3 & 148 & [63] \\
\hline Butyl stearate & 19,19 & 140,200 & [59], [9] \\
\hline Propyl palmitate & 19 & 186 & {$[59]$} \\
\hline $\begin{array}{c}\text { Isopropyl } \\
\text { stearate }\end{array}$ & $14-18$ & 142 & [9] \\
\hline $\begin{array}{l}\text { Dimethyl- } \\
\text { sulfoxide }\end{array}$ & 16.5 & 86.7 & [9] \\
\hline Glycerin & $17.9,16.85$ & $198.7,198.5$ & {$[64],[65]$} \\
\hline A15 & 15 & 205 & [66] \\
\hline A16 & 16 & 225 & [66] \\
\hline A17 & 17 & 235 & [66] \\
\hline A18 & 18 & 155 & [66] \\
\hline A19 & 19 & 150 & [66] \\
\hline A20 & 20 & 160 & [66] \\
\hline Pure Temp15 & 15 & 182 & [67] \\
\hline Pure Temp18 & 18 & 192 & [68] \\
\hline Pure Temp20 & 20 & 171 & [69] \\
\hline Palm oil & 17.27 & 127.3 & {$[70]$} \\
\hline $\begin{array}{c}\text { Palm } \\
\text { oil/xGnPSSPCM }\end{array}$ & 18.33 & 77.18 & {$[70]$} \\
\hline \multicolumn{4}{|c|}{ Salt hydrates } \\
\hline $\mathrm{KF} 4 \mathrm{H} 2 \mathrm{O}$ & 18.5 & 231 & [59] \\
\hline K2HPO4 4H2O & 18.5 & 231 & [59] \\
\hline SP15 & $15-17$ & 180 & [71] \\
\hline S15 & 15 & 180 & [66] \\
\hline S17 & 17 & 155 & [66] \\
\hline S18 & 18 & 145 & [66] \\
\hline S19 & 19 & 175 & [66] \\
\hline S20 & 20 & 195 & [66] \\
\hline \multicolumn{4}{|c|}{ Eutectics } \\
\hline E19 & 19 & 146 & [72] \\
\hline $\begin{array}{c}\mathrm{Na} 2 \mathrm{SO} 4-\mathrm{NaCl}- \\
\mathrm{H} 2 \mathrm{O}\end{array}$ & 18 & & [9] \\
\hline $\begin{array}{c}\mathrm{CaCl} 2-6 \mathrm{H} 2 \mathrm{O}- \\
\mathrm{NH} 4 \mathrm{NO} 3- \\
\mathrm{NH} 4 \mathrm{Br} \\
\end{array}$ & 20 & 141 & [9] \\
\hline $\begin{array}{l}\text { Capric-lauric } \\
\text { acid }\end{array}$ & 18 & 148 & [9] \\
\hline MT17 & 17.5 & 77 & [73] \\
\hline $\begin{array}{l}\text { Exadecane- } \\
\text { octadecane }\end{array}$ & 18.5 & 121 & [74] \\
\hline $\begin{array}{c}\text { Methyl } \\
\text { Palmitate- Ethyl } \\
\text { Palmitate } \\
\end{array}$ & 20 & 178 & {$[75]$} \\
\hline $\begin{array}{c}\text { Methyl Oleate- } \\
\text { Methyl } \\
\text { Palmitate }\end{array}$ & 19 & 174 & {$[75]$} \\
\hline Emerest 2325 & 20 & 134 & [59] \\
\hline Emerest 2326 & 20 & 139 & [59] \\
\hline $\begin{array}{l}\mathrm{CaCl} 26 \mathrm{H} 2 \mathrm{O}- \\
\mathrm{CaBr} 26 \mathrm{H} 2 \mathrm{O}\end{array}$ & 14.7 & 140 & {$[14]$} \\
\hline
\end{tabular}




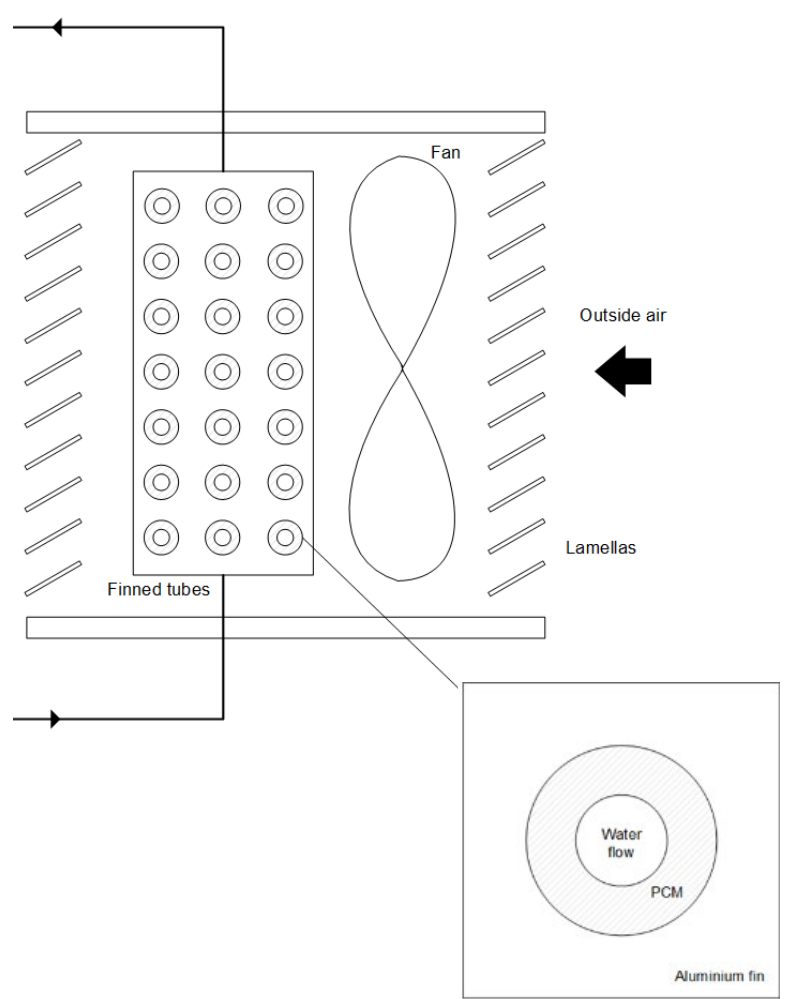

Figure 2: Cooling system assembly

Figure 3 outlines the system. The novelty of the system is depicted in the heat exchange which is achieved in one single phase transition from outdoor air to the two pipe chilled beam system's water circuit.

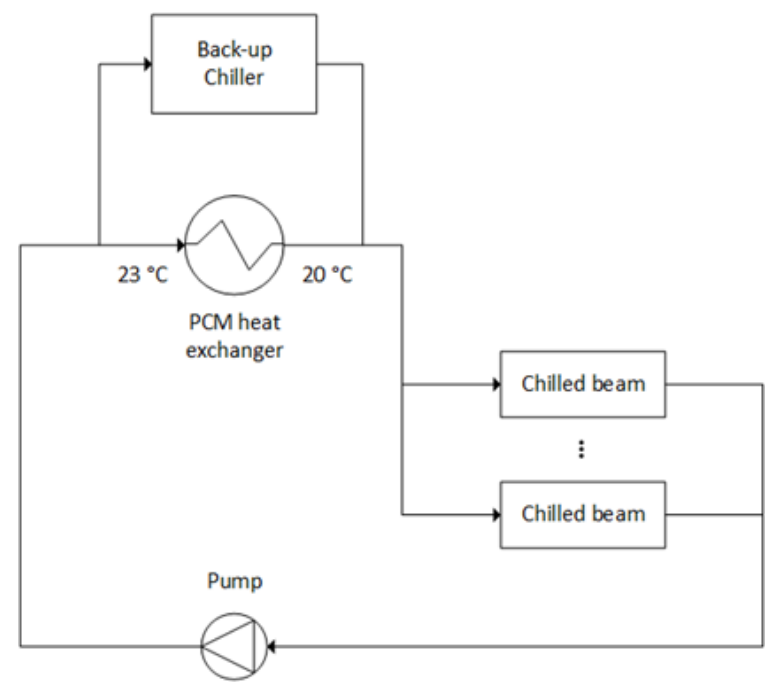

Figure 3: Overall system's assembly

\section{Concluding remarks}

Studies based on PCM materials and their application for heat exchangers and air conditioning chilled water systems were reviewed in this paper. Numericalsimulation and experimental studies demonstrated that the implementation of PCM in LHTES systems leads to a significant reduction of the peak load. The thermal properties of the selected PCM, the heat exchanger design, the use of fins or spheres for PCM encapsulation are the most significant considerations for the development of chilled water air conditioning systems with PCM in the existing literature. Paraffins and fatty acids were considered as PCM in the majority of the experimental studies reviewed. Although the implementation of PCMs in cooling systems is a promising technique there is still research to be done. The use of free cooling potential in a PCM-based heat exchanger integrated with a two pipe chilled beam system is expected to bring in remarkable energy savings.

This work is part of an ongoing $\mathrm{PhD}$ project at Danish Building Research Institute, Aalborg University in collaboration with Lindab Comfort $\mathrm{A} / \mathrm{S}$. The project is financially supported by ELFORSK, a research and development program administrated by Danish Energy.

\section{References}

[1] X. Cao, X. Dai, and J. Liu, Energy Build., 128, 198-213, (2016)

[2] G. Paoletti, R. Pascual Pascuas, R. Pernetti, and R. Lollini, Buildings, 7, 43, (2017)

[3] A. Prieto, U. Knaack, T. Klein, and T. Auer, Renew. Sustain. Energy Rev., 71, 89-102, (2017)

[4] B. Sanner, R. Kalf, A. Land, and K. Mutka, P. Papillon, G. Stryi-Hipp, W. Weiss, European Technology Platform on Renewable Heating \& Cooling, (2011)

[5] ASHRAE, "Standard 55 -Thermal Environmental Conditions for Human Occupancy," (2010)

[6] European Comission, "Indoor air pollution: new EU research reveals higher risks than previously thought," Eur. Com., (2003)

[7] R. L. Fehr, Guid. to Build. Energy Effic. Homes, 103-130, (2009)

[8] D. W. Hawes, D. Feldman and D. Banu, Energy Build., 20, 77-86, (1993)

[9] J. Kośny, PCM-Enhanced Building Components, (2015)

[10] A. Fallahi, G. Guldentops, M. Tao, S. GranadosFocil, and S. Van Dessel, Appl. Therm. Eng., 127, 1427-1441, (2017)

[11] W. Su, J. Darkwa, and G. Kokogiannakis, Renew. Sustain. Energy Rev., 48, 373-391, (2015)

[12] M. Fatih Demirbas, Energy Sources, Part B Econ. Plan. Policy, 1, 85-95, (2006)

[13] C. Barreneche, A. Solé, L. Miró, I. Martorell, A. I. Fernández, and L. F. Cabeza, Thermochim. Acta, 553, 23-26, (2013)

[14] N. Xie, Z. Huang, Z. Luo, X. Gao, Y. Fang, and Z. Zhang, Appl. Sci., 7, 1317, (2017)

[15] A. S. Fleischer, Thermal Energy Storage Using Phase Change Materials Fundamentals and Applications, (2015)

[16] Z. Yinping, J. Yi, and J. Yi, Meas. Sci. Technol., 
10, 201-205, (1999)

[17] M. Fuensanta, U. Paiphansiri, M. D. RomeroSánchez, C. Guillem, A. M. López-Buendía, and K. Landfester, Thermochim. Acta, 565, 95-101, (2013)

[18] C. Liu, Z. Rao, J. Zhao, Y. Huo, and Y. Li, Nano Energy, 814-826, (2015)

[19] W. Lu and S. A. Tassou, Appl. Energy, 91, 366374, (2012)

[20] M. K. Rathod and J. Banerjee, Renew. Sustain. Energy Rev., 18, 246-258, (2013)

[21] R. H. Müller, Anal. Chem., 35, 103A-105A, (2012)

[22] S. R. Sandler, W. Karo, J.-A. Bonesteel, and E. M. Pearce, Polym. Synth. Charact., 1, 108-119, (2007)

[23] R. Jacob and F. Bruno, Renew. Sustain. Energy Rev., 48, 79-87, (2015)

[24] V. V. Tyagi, S. C. Kaushik, S. K. Tyagi, and T. Akiyama, Renew. Sustain. Energy Rev., 15, 1373-1391, (2011)

[25] E. M. Shchukina, M. Graham, Z. Zheng, and D. G. Shchukin, Chem. Soc. Rev., 47, 4156, (2018)

[26] T. E. Alam, J. S. Dhau, D. Y. Goswami, and E. Stefanakos, Appl. Energy, 154, 92-101, (2015)

[27] A. Jamekhorshid, S. M. Sadrameli, and M. Farid, Renew. Sustain. Energy Rev., 31, 531-542, (2014)

[28] X. Q. Zhai, X. L. Wang, T. Wang, and R. Z. Wang, Renew. Sustain. Energy Rev., 22, 108120, (2013)

[29] V. Morcos, Sol. Wind Technol., 7, 197-202, (1990)

[30] M. Lacroix, Int. J. Heat Mass Transf., 36, 20832092, (1993)

[31] Y. W. Zhang and A. Faghri, Int. J. Heat Mass Transf., 39, 3165-3173, (1996)

[32] A. Trp, Sol. Energy, 79, 648-660, (2005)

[33] A. Trp, K. Lenic, and B. Frankovic, Appl. Therm. Eng., 26, 1830-1839, (2006)

[34] M. Akgün, O. Aydin, and K. Kaygusuz, Appl. Therm. Eng., 28, 405-413, (2008)

[35] M. J. Hosseini, M. Rahimi, and R. Bahrampoury, Int. Commun. Heat Mass Transf., 50, 128-136, (2014)

[36] H. Eslamnezhad and A. B. Rahimi, Appl. Therm. Eng., 113, 813-821, (2017)

[37] M. Mastani Joybari, F. Haghighat, and S. Seddegh, Energy Build., 139, 426-438, (2017)

[38] L. Jian-you, Sol. Energy, 82, 977-985, (2008)

[39] W. J. Hu, M. N. Chang, Y. Gao, Q. L. Zhang, L. Y. Yang, and D. Y. Li, Procedia Eng., 205, 30883095, (2017)

[40] W. Youssef, Y. T. Ge, and S. A. Tassou, Energy Convers. Manag., 157, 498-510, (2018)
[41] E. S. Fath, Energy Convers. Manag., 31, 149-155, (1991)

[42] J. R. Balikowski and J. C. Mollendorf, J. Heat Transfer, 129, 265, (2007)

[43] M. Medrano, M. O. Yilmaz, M. Nogués, I. Martorell, J. Roca, and L. F. Cabeza, Appl. Energy, 86, 2047-2055, (2009)

[44] A. Maccarini, G. Hultmark, N. C. Bergsøe, and A. Afshari, Sustain. Cities Soc., 42, 384-395, (2018)

[45] X. Y. Li, Y. Cui, and Y. Y. Wu, ICIC $2010-3 r d$ Int. Conf. Inf. Comput., 4, 23-26, (2010)

[46] S. Wu, G. Fang, and X. Liu, Int. J. Therm. Sci., 49, 1752-1762, (2010)

[47] R. Parameshwaran, S. Harikrishnan, and S. Kalaiselvam, Energy Build., 42, 1353-1360, (2010)

[48] R. Parameshwaran and S. Kalaiselvam, Energy Build., 69, 202-212, (2014)

[49] M. De Falco, M. Capocelli, and A. Giannattasio, Energy Build., 122, 1-10, (2016)

[50] D. Zhao and G. Tan, Appl. Energy, 138, 381-392, (2015)

[51] X. Y. Li, L. Yang, X. L. Wang, X. Y. Miao, Y. Yao, and Q. Q. Qiang, Energy, 150, 591-600, (2018)

[52] F. Bruno, N. H. S. Tay, and M. Belusko, Energy Build., 76, 347-353, (2014)

[53] N. H. S. Tay, M. Belusko, and F. Bruno, Energy Build., 50, 234-242, (2012)

[54] M. Virta D. Butler, J. Gräslund, J. Hogeling, E. Lund Kristiansen, M. Reinikainen, G. Svensson, Chilled Beams Application Guide Book, Rehva Guidebook no 5, (2005)

[55] A. Maccarini, M. Wetter, A. Afshari, G. Hultmark, N. C. Bergsøe, and A. Vorre, Energy Build., 134, 234-247, (2017)

[56] A. Maccarini, A two-pipe system for simultaneous heating and cooling of office buildings, (2017)

[57] F. Souayfane, F. Fardoun, and P. H. Biwole, Energy Build., 129, 396-431, (2016)

[58] C. Arkar, B. Vidrih, and S. Medved, Int. J. Refrig., 30, 134-143, (2007)

[59] H. Akeiber, P. Nejat, M. Z. Abd. Majid, M. A.Wahid, F. Jomehzadeh, I. Z. Famileh, J. K. Calautit, B. R. Hughes, S. A. Zaki, Renew. Sustain. Energy Rev., 60, 1470-1497, (2016)

[60] Retrieved from URL: https://www.rubitherm.eu/media/products/datash eets/Techdata_RT15_EN 06082018.PDF

[61] Retrieved from URL: https://www.rubitherm.eu/media/products/datash eets/Techdata_RT18HC EN_06082018.PDF

[62] D. Zhou, C. Y. Zhao, and Y. Tian, Appl. Energy, 92, 593-605, (2012)

[63] A. Hasan and A. A. Sayigh, Renew. Energy, 4, 69-76, (1994) 
[64] A. Sharma, V. V. Tyagi, C. R. Chen, and D. Buddhi, Renew. Sustain. Energy Rev., 13, 318345, (2009)

[65] S. Kalaiselvam, K. Sureshkumar, and V. Sriram, Therm. Sci., 20, 1543-1554, (2016)

[66] Retrieved from URL:

http://www.pcmproducts.net/files/PCM\%20Ran ge\%202018\%20Rev_D\%20Compressed.pdf

[67] Retrieved from URL:

http://www.puretemp.com/stories/puretemp-15$\underline{\text { tds }}$

[68] Retrieved from URL:

http://www.puretemp.com/stories/puretemp-18$\underline{\text { tds }}$

[69] Retrieved from URL:

http://www.puretemp.com/stories/puretemp-20$\underline{\mathrm{tds}}$

[70] S. Wi, J. Seo, S. G. Jeong, S. J. Chang, Y. Kang, and S. Kim, Sol. Energy Mater. Sol. Cells, 143, 168-173, (2015)

[71] Retrieved from URL:

https://www.rubitherm.eu/media/products/datash eets/Techdata -SP15 EN 15112018.PDF

[72] U. Stritih and V. Butala, Int. J. Refrig., 33, 16761683, (2010)

[73] M. Yamaha, S. Misaki, and D. Shinya Misaki, 9669, (2011)

[74] K. Nagano, S. Takeda, T. Mochida, K. Shimakura, and T. Nakamura, Energy Build., 38, 436-446, (2006)

[75] G. J. Suppes, M. J. Goff, and S. Lopes, Chem. Eng. Sci., 58, 1751-1763, (2003) 